\title{
Olhar, o corpo e as imagens rupestres: uma proposta de reflexão
}

\author{
Ana Elisa Antunes Viviani ${ }^{7}$ \\ DOI 10.20396/eha.vil4.3456
}

Em tempos de hiperabundância de imagens, facilmente reproduzíveis, compartilháveis e "instagramáveis", onipotentes e onipresentes, que se lançam aos nossos olhares, independentemente de nossas vontades, parece-nos difícil imaginar um mundo em que seria necessário mobilizar grande disposição física e psíquica para que pudessem ser criadas. Essas imagens provavelmente geravam grandes expectativas, alimentando memórias, sonhos e imaginações.

As imagens a que nos referimos são aquelas localizadas no Grande Abrigo Santana do Riacho, em Minas Cerais, criadas em um período compreendido entre 8.000 e 2.500 anos A.P. (antes do presente).

Para refletirmos sobre a relação entre o olhar e as pinturas rupestres, recorremos às considerações do historiador da arte Hans Belting a respeito da relação entre imagem, corpo e meio, ao conceito de ambiente da Semiótica da Cultura, e aos conceitos de aura, valor de exposição e valor de culto de Walter Benjamin.

Imagem, corpo e meio

A investigação de Hans Belting sobre as imagens é bastante interessante para uma reflexão que transborda vieses estéticos e busca leituras antropológicas, como seria o caso do horizonte epistemológico proposto pela antropologia histórica alemã, representada por nomes como Christoph Wulf e Gunther Gebauer, mas também os estudos de história sociocultural da tradição francesa, como é o caso de Jacques Le Goff e Jean-Pierre Vernant, entre outros.

Belting recupera o importante papel do corpo como articulador da imagem, de forma que compreende o ser humano como "lugar das imagens". Para ele, portanto, as imagens não são apenas um produto da percepção; são "resultado de uma simbolização pessoal ou coletiva"2.

A contribuição de Belting que nos interessa para abordar o tema das pinturas rupestres po- 


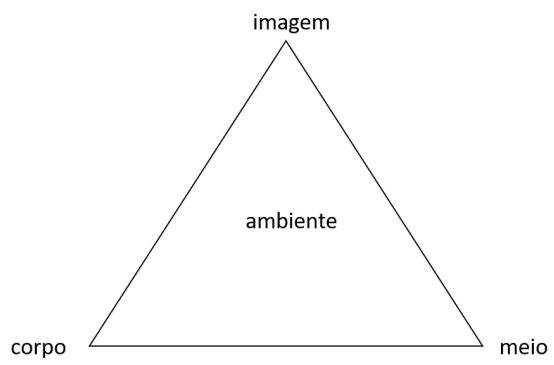

[Figura 1] Representação da triangulação imagem, corpo e meio, de Hans Belting.

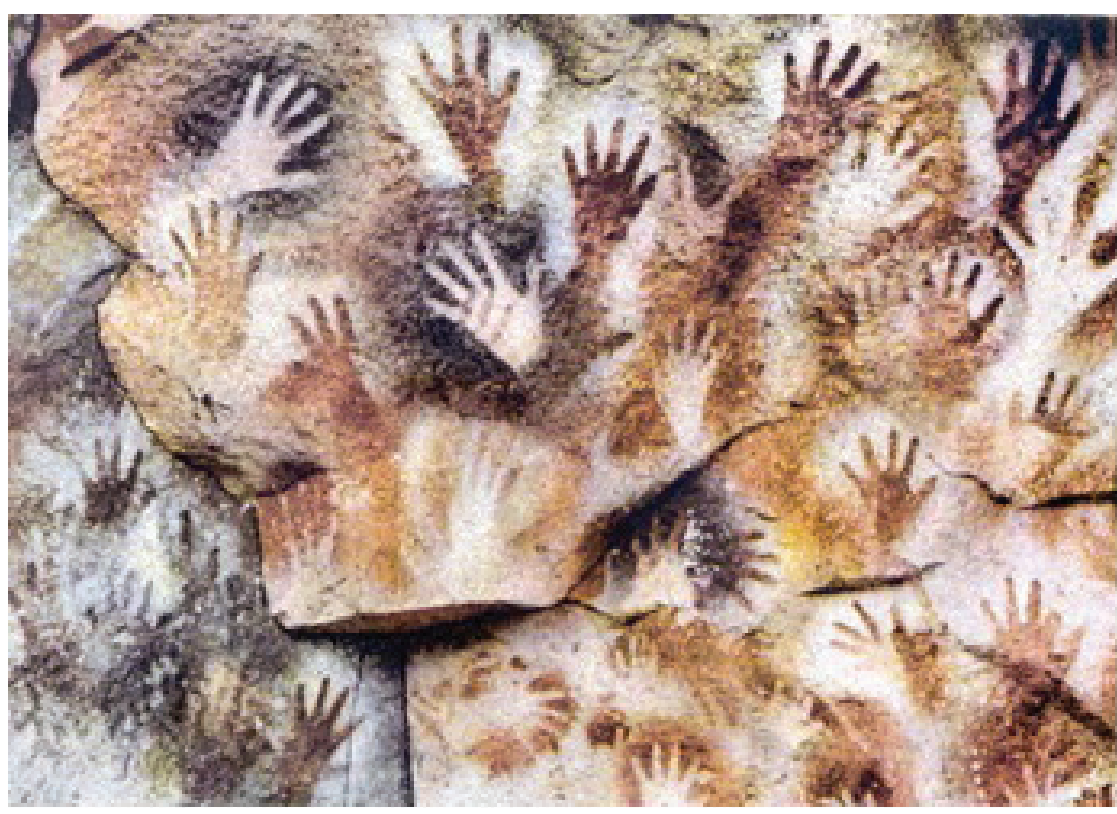

[Figura 2] Cueva de las Manos, 13.000 - 9.000 anos A.P., Província de Santa Cruz, Patagônia Argentina. Fonte: World Heritage Comittee, UNESCO.

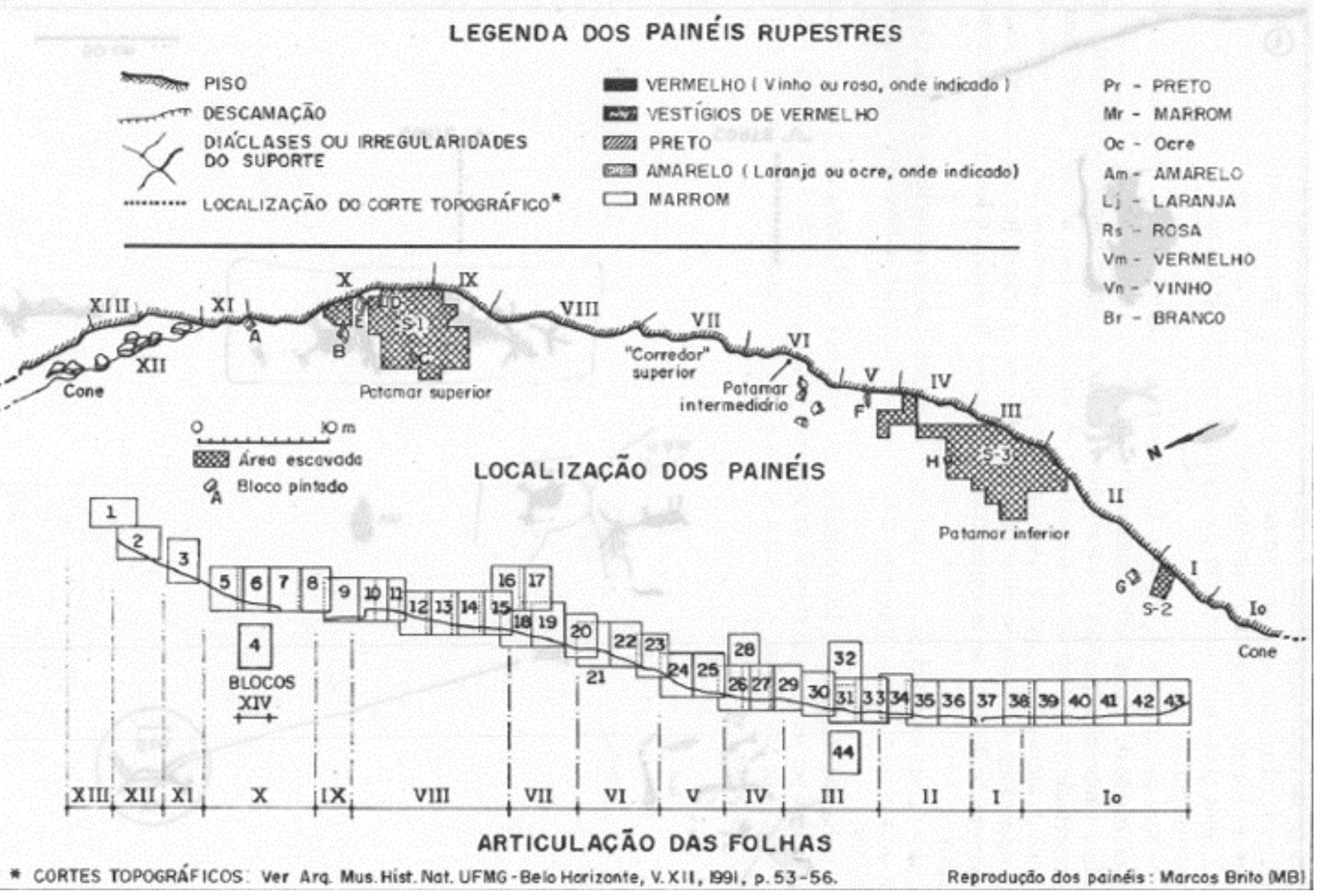

[Figura 3] Grande Abrigo Santana do Riacho - corte topográfico. Fonte: PROUS e BAETA (1992-1993a, p. 195. 
deria se resumir nas seguintes perguntas: onde se localiza uma imagem? em nosso olhar, no seu suporte, ou no ambiente? Como Belting escreve, uma imagem pode até "viver em uma obra de arte, mas não coincide com ela."3 Assim, ele descola a imagem de seu suporte e ressalta seu caráter ambivalente, porque ela se refere sempre a um corpo e à sua medialidade, o que a distingue do signo.

Esse objeto fugidio, portanto, faz com que emerja sua natureza não reificável, uma vez que sua existência oscila entre o físico e o mental ${ }^{4}$. Assim, para o autor, uma imagem possui duas existências, uma endógena, isto é, que habita o interior dos olhares, e outra exógena, que existe em sua visualidade.

Isso significa, então, que uma imagem participa da nossa percepção não apenas sensorialmente, isto é, como algo que o olho captura e que se encerra em nosso cérebro, mas como algo que participa ativamente da nossa imaginação, da nossa existência.

"Ocorre uma metamorfose quando as imagens vistas se transmutam em imagens recordadas que, doravante, encontram um novo lugar no nosso arquivo imaginal. Começamos por despojar do seu corpo as imagens exteriores, que 'chegamos a ver', e num segundo momento de novo as corporalizamos: tem lugar um intercâmbio entre o seu meio-suporte e o nosso corpo que, por seu lado constitui um meio natural" 5 .

Diferentemente da maior parte das pesquisas sobre imagens, que focam no signo icônico, para Belting, portanto, as imagens estão inexoravelmente ligadas ao corpo. Elas podem dispender de seu suporte ou meio, mas nunca do corpo, que as origina, Ihes dá sentido, rememora. Por isso, as imagens devem ser pensadas necessariamente como uma relação que se dá entre corpos e meios.

As imagens acontecem entre nós, que as olhamos, e seus meios, com os quais elas respondem ao nosso fitar. Elas se fiam em dois atos simbólicos que envolvem nosso corpo vivo: 0 ato de fabricação e o de percepção, sendo este último um propósito do anterior ${ }^{6}$.

Para o autor, então, a imagem necessita de um meio para que adquira visibilidade. Meio e imagem são "como duas faces de uma mesma moeda, que são impossíveis separar, embora estejam separadas pelo olhar e signifiquem coisas diferentes"7.

E o meio:

\footnotetext{
3 BELTING, Hans. Por uma antropologia da imagem. Concinnitas, ano 6, vol. 1, n. 8, julho 2005, p. 66. Aqui, o autor trata da questão dos termos em inglês Image, que poderia ser traduzido como imagem ou figura, por exemplo, e Picture, que poderia ser traduzido como pintura, quadro, retrato.

4 Id., 2014, p. 10.

5 Id., ib., p. 34.

6 Id., 2005, p. 69

7 Id., 2014, p. 23.
} 
[...] só adquire o seu verdadeiro significado quando compreendido no contexto da imagem e do corpo. Ele fornece, por assim dizer, o elo em falta, pois, desde logo, o meio torna-nos capazes de perceber as imagens de maneira a que não confundamos nem com os corpos reais nem com as simples coisas ${ }^{8}$.

Assim, através dessa triangulação, que Belting credita a Jean-Pierre Vernant e seus estudos sobre o kolossos e o eidòlon, formada pela imagem + corpo + meio (Fig.1), cada vértice tem peso igual aos demais, e é por meio dessa triangulação que se encontra o ambiente.

A pesquisadora Marie-José Mondzain chama a atenção para esse aspecto ambivalente da imagem ao afirmar que ela é "ao mesmo tempo uma operadora em uma relação e objeto produzido por essa relação" ". Ela ilustra essa característica da imagem com a impressão das mãos nas paredes das cavernas e das $\operatorname{rochas}^{10}$ (Fig. 2). "A imagem de si é uma prova de separação, a instauração de um regime de separação e de uma subjetividade desatada"11. Concomitantemente à criação da imagem de si, surge o sujeito imaginante. É nesse gesto, aparentemente arcaico, que encontramos "o cenário fundador de toda operação imaginal e icônica"12, gesto do qual não nos desvencilhamos.

Então, se há uma ruptura no entendimento da imagem como coisa em si ou com valor em si, ela, portanto, só pode ser compreendida quando integrada em seu ambiente.

O conceito de ambiente é bastante caro à Semiótica da Cultura, que recupera a Teoria da Significação do biólogo alemão Jakob von Uexküll (1864-1944). Dele, absorve-lhe a noção de Umwelt³, isto é, ambiente, em alemão. Uexküll utiliza o termo no sentido de nicho ecológico, isto é, a noção de que cada ser vivo cria para si um ambiente, enquanto a semiótica da cultura o utiliza em favor de uma espécie de pensamento ambiental. Assim, não se trata do ambiente análogo a uma ideia de natureza ou paisagem, mas de um ambiente no qual os seres vivos impregnam-se e por ele são impregnados.

Vejamos, então, como o triângulo de Belting e o conceito de ambiente são empregados para compreender essa relação entre o olhar e as pinturas rupestres.

\footnotetext{
8 Id., ib., p. 24.

9 MONDZAIN, Marie-José. A imagem entre proveniência e destinação. In: ALLOA, Emmanuel (org). Pensar a imagem. Belo Horizonte: Autêntica, 2015, p. 39

10 Esse fenômeno é observável em diversas culturas pré-históricas no mundo e em algumas do Brasil.

11 Id., ib., p. 42

12 Id., ib., p. 43

13 Umwelt significa ambiente, mas podemos entender melhor o significado se separarmos "Um", que pode significar "entorno", "em volta", "perto de", e "Welt", que significa mundo. Teremos, portanto, algo como "mundo do entorno". Essa aplicação do termo Umwelt por Uexküll impactou não apenas a biologia, mas as ciências humanas em geral, pois colocou em xeque a perspectiva antropocêntrica de entendimento do mundo. "A grande revolução do conceito de Umwelt observou que o mundo não era único e hierarquicamente ordenado; ao contrário, todas as espécies vivas, das mais elementares até o homem, nele encontrariam espaços adequados e interinfluentes, mais independentes uns dos outros". (FERRARA, Lucrécia D’Alessio. Comunicação, mediações, interações. São Paulo: Paulus, 2015, p.44)
} 
Imagens rupestres mineiras: Tradição Planalto e o Grande Abrigo Santana do Riacho

As imagens pré-históricas da Tradição Planalto ${ }^{14}$ localizam-se no Estado de Minas Gerais e caracterizam-se pela predominância de figuras zoomorfas, grafismos, poucas figuras humanas, mas diferenças estilísticas marcantes entre elas, tanto entre sítios arqueológicos distintos, quanto em um mesmo painel pictórico.

O Grande Abrigo Santana do Riacho é um sítio arqueológico pertencente ao município Santana do Riacho, aos pés da Serra do Cipó, e distante cerca de 90 km de Belo Horizonte. O município possui ainda diversos outros sítios com pinturas rupestres, mas o Grande Abrigo é um exemplar único, não apenas na região, mas para todas as pesquisas relativas à pré-história brasileira por dois motivos: os sepultamentos de mais de 40 corpos encontrados nos períodos mais antigos de ocupação do abrigo, cerca de 12.000 anos A.P., e portanto em período pleistocênico, e seu mural pictural de mais de cem metros lineares de extensão com cerca de 2.000 figuras registradas e distribuídas em dois patamares (ou plataformas) que alcançam até 5 metros de altura.

Neste trabalho não nos prolongaremos nos aspectos pictóricos dos painéis, pois o que pretendemos explorar é a relação que nosso olhar estabelece com essas imagens. Para isso, recorremos às investigações realizadas no início da década de 1990 sobre os restos de pigmentos e de tintas localizados nas escavações deste sítio.

Os pesquisadores descobriram que muitos dos vestígios encontrados eram fabricados a partir de matérias-primas localizadas em regiões distantes, como é o caso dos blocos de hematita, distantes cerca de 30 km (na região mais ao norte) ou do Quadrilátero Ferrífero, cerca de 100km (ao sul do Estado). É o caso também de vestígios dos fragmentos de cupinzeiro, que fornecem pigmentos alaranjados, em tons mostarda e marrom, localizados no Planalto de Lagoa Santa, e indicando o seu transporte por dezenas de quilômetros.

O que é possível deduzir é que havia um processo bastante complexo e laborioso na fabricação das tintas utilizadas nas pinturas parietais, além da própria complexidade das pinturas em si. Ou seja, os grupos que criaram essas pinturas faziam um grande investimento físico, psíquico e social na elaboração das mesmas, deslocando-se por distâncias razoavelmente longas para encon-

\footnotetext{
14 A ciência arqueológica praticada no Brasil tem por tradição organizar e agrupar as imagens rupestres de acordo com seus aspectos formais, a fim de facilitar o trabalho de identificação e estudo, não implicando nenhuma relação com comunidades étnicas pré-históricas. É nesse sentido que as primeiras imagens cientificamente estudadas receberam o nome de Tradição Planalto, fazendo referência aos Planaltos Atlântico e Central onde, geograficamente, se situa o Estado de Minas Cerais.
} 
trar as matérias-primas desejadas, realizar o trabalho de obtenção de pigmentos e corantes, o que deveria durar meses e, por fim, elaborar o trabalho pictórico.

Esse empenho todo (para além da luta diária pela subsistência), portanto, teria que ser bastante planejado a fim de ser empregado na atividade pictural. É possível, também, que esse processo de elaboração de tintas e criação de imagens integrasse diversas outras práticas culturais.

Segundo a pesquisadora Alenice Baeta, retomando o importante livro de Walter Neves e Luis Piló15, possivelmente as populações pré-históricas mineiras realizavam vários rituais durante o ciclo anual, como ritos de passagem, funerais, e de reverência às forças da natureza. Sua relação com o mundo animal deveria ser muito complexa, o que seria atestada pela abundante presença de figuras de animais nas pinturas parietais, e mediada por um enorme repertório mítico.

Além disso, é possível supor que esses ambientes imagéticos contavam com o apoio de músicas e narrativas, fortalecendo os laços sociais da comunidade e amenizando sua fragilidade física e psíquica. Como escreve Norval Baitello Jr.,

construir um ambiente e situar-se nele reduz a fragilidade do estar só. E, para os entrelaçamentos, somente corpos podem ser pontos de germinação dos ambientes. Corpos narrativizam tais entrelaçamentos que geram ambientes, e os ambientes são os pressupostos para a continuidade, para a sustentabilidade, para a sobrevida do corpo nos outros corpos e nos corpos-outros, na materialidade dos meios que facilitam a nodação entre os corpos. ${ }^{16}$

Assim, concluímos que o grande investimento físico e psíquico na elaboração do painel pictural estaria muito próximo daquilo que Walter Benjamin chama de valor de culto da imagem. Isto é, o olhar que estabelecemos com as imagens rupestres relevaria sua aura.

Sobre o olhar e a imanência das pinturas rupestres

Em A obra de arte na era de sua reprodutibilidade técnica, Walter Benjamin fala do valor de culto da obra artística e de seu caráter único, isto é, sua aura. Trata-se da existência única da imagem, fincada no "aqui e agora" e em total oposição à sua reprodutibilidade técnica. A aura é "[...] uma figura singular, composta de elementos espaciais e temporais: a aparição única de uma obra

15 NEVES, Walter A.; PILÓ, Luis Beethoven. O povo de Luzia: em busca dos primeiros americanos. São Paulo: Globo, 2008.

16 BAITELLO JUNIOR, Norval. Corpo e imagem: comunicação, ambientes, vínculos. In: RODRIGUES, David (org). Os valores e as atividades corporais. São Paulo: Summus, 2008, p. 100. 
distante, por mais perto que ela esteja"17.

In loco, quando na presença do painel rupestre, passamos os dedos pela rocha e sentimos suas ranhuras e sua frieza, percebemos a brisa e ouvimos os sons do entorno, nosso olfato sente o frescor da vegetação e o aroma mineral que emana da terra e das pedras. Benjamin traz essa sensorialidade ao escrever: "Observar, em repouso, numa tarde de verão, uma cadeia de montanhas no horizonte, ou um galho, que projeta sua sombra sobre nós, significa respirar a aura dessas montanhas, desse galho."18

Portanto, o caráter imanente das imagens também está relacionado ao que Benjamin chama de recepção tátil, em oposição à recepção ótica. Quem se recolhe numa obra, "[...] mergulha dentro dela e nela se dissolve [...]." ${ }^{\prime 19}$ (1994, p. 193). Assim, as pinturas rupestres contêm em si algo mais que apenas a descrição de cenas de caça. Carregam expectativas e mobilizam intenções para além daquilo imediatamente dado pelas suas formas.

Tais imagens, portanto, poderiam ser comparadas às imagens artísticas e seu valor de culto, cujas qualidades estão intrínsecas em si. São, portanto, imanentes, isto é, entregam-se ao olhar do observador.

No caso das imagens mediáticas, seu valor é transferido para o suporte e o ambiente, adquirindo valor de exposição. As imagens tornam-se transcendentes. Elas podem nem ter valor estético, nem de novidade, mas criam ambientes que se alimentam do olhar.

17 BENJAMIN, Walter. Magia e técnica, arte e política: ensaios sobre literatura e história da cultura. $7^{\mathrm{a}}$ ed. São Paulo: Brasiliense, 1994. Obras escolhidas, v. 1, p. 170.

18 Id., ib.

19 Id., ib., p. 193. 


\section{Referências bibliográficas}

BAETA, Alice Motta. Os grafismos rupestres e suas unidades estilísticas no Carste de Lagoa Santa e Serra do Cipó MG. Janeiro de 2011. Tese de doutorado. MAE-USP, 2011.

BAITELLOJUNIOR, Norval. Corpo e imagem: comunicação, ambientes, vínculos. In: RODRIGUES, David (org). Os valores e as atividades corporais. São Paulo: Summus, 2008, pp. 95-112.

BELTING, Hans. A imagem autêntica. Porto: Dáfne Editora, 2011.

BELTING, Hans. Antropologia da imagem. Lisboa: KKYM + EAUM, 2014.

BELTING, Hans. Por uma antropologia da imagem. Concinnitas, ano 6, volume 1, número 8, julho 2005, pp. 64-78.

BENJAMIN, Walter. A obra de arte na era de sua reprodutibilidade técnica. In: Magia e técnica, arte e política. $7^{\text {a }}$ ed. São Paulo: Brasiliense, 1994.

CASTRO e SILVA, Martha Maria; TORRI, Marcos Breno. Capítulo 13: Os pigmentos e 'corantes' encontrados nas escavações do Grande Abrigo Santana do Riacho. IV. Produção Experimental e Utilização de Pigmentos: à procura das fórmulas pré-históricas. Arquivos do Museu de História Natural. Belo Horizonte: UFMG, 1991. Vol. XII, pp. 299-404.

COSTA, G.M.; ]ESUS FILHO, M.F.; MALTA, I.M.; PROUS, A.; SILVA, M.M.C; SOUZA, L.A.C.; TORRI, M.B. Capítulo 13: Os pigmentos e 'corantes' encontrados nas escavações do Grande Abrigo Santana do Riacho. Arquivos do Museu de História Natural. Belo Horizonte: UFMG, 1991. Vol. XII, pp. 299-404.

FERRARA, Lucrécia d’Alessio. Comunicação, mediações, interações. São Paulo: Paulus, 2015.

MALTA, lone Mendes. Capítulo 13: Os pigmentos e 'corantes' encontrados nas escavações do Grande Abrigo Santana do Riacho. II. Análise Macroscópica dos pigmentos das escavações de Santana do Riacho. Arquivos do Museu de História Natural. Belo Horizonte: UFMG, 1991. Vol. XII, pp. 299-404.

MONDZAIN, Marie-José. A imagem entre proveniência e destinação. In: ALLOA, Emmanuel (org). Pensar a imagem. Belo Horizonte: Autêntica, 2015.

NEVES, Walter A.; PILÓ, Luis Beethoven. 0 povo de Luzia: em busca dos primeiros americanos. São Paulo: Globo, 2008.

PROUS, André. As primeiras populações do Estado de Minas Gerais. In: TENÓRIO, Maria Cristina, org. Pré-história da Terra Brasilis. Rio de Janeiro: UFR], 2000, pp. 101-114.

PROUS, André. Exemplos de análises rupestres punctuais. Arquivos do Museu de História Natural. Belo Horizonte: UFMG, 1985. Volume X.

PROUS, André. Capítulo 13: Os pigmentos e 'corantes' encontrados nas escavações do Crande Abrigo Santana do Riacho. I. Problemas Gerais. Arquivos do Museu de História Natural. Belo Horizonte: UFMG, 1991. Vol. XII.

PROUS, André; BAETA, Alenice. Capítulo 20: O levantamento geral dos grafismos rupestres de Santana do Riacho. Arquivos do Museu de História Natural. Belo Horizonte: UFMG, 1992-1993a. Vol. XIII-XIV.

PROUS, André; BAETA, Alenice. Capítulo 21: Elementos de cronologia, descrição de atributos e tipologia. Arquivos do Museu de História Natural. Belo Horizonte: UFMG, 1992-1993b. Vol. XIII-XIV.

PROUS, André; BAETA, Alenice. Capítulo 22: Análise de conjunto da arte rupestre de Santana do Riacho. Arquivos do Museu de História Natural. Belo Horizonte: UFMG, 1992-1993C. Vol. XIII-XIV. 